\title{
Low energy ion bombardment on c-Ge surfaces
}

\author{
J Dekker, H J W Zandvliet and A van Silfhout, University of Twente, Faculty of Applied Physics, \\ P.O. Box 217, 7500 AE Enschede, The Netherlands
}

\begin{abstract}
Amorphous germanium thin films (25-60A) were prepared by low energy $(500,800 \mathrm{eV})$ bombardment of noble gas ions ( $\mathrm{Ne}, \mathrm{Ar}, \mathrm{Kr}$ ) on $\mathrm{c}$-Ge(001). The films were examined by spectroscopic ellipsometry and analysed using linear regression analysis (LRA). The most probable composition of the damaged toplayer is that of void free amorphous germanium, comparable with those obtained by dc-magnetron sputtering. The results are in excellent agreement with Monte Carlo simulations of the transport of ions in matter (TRIM86).
\end{abstract}

The influence of ion bombardment on the structure of the germanium or silicon lattice has been the subject of several investigations $^{2-5}$. The various effects induced by low energy ion bombardment in the outer layers of a solid-lattice damage, ion implantation, surface roughness, sputtering and surface state changes - are reflected in changes of the complex dielectric constant $\varepsilon$, which can be measured by means of spectroscopic ellipsometry ${ }^{2-5}$.

This paper reports noble gas ion bombardment studies carried out on Ge and analysed using spectroscopic ellipsometry (SE) combined with linear regression analysis (LRA) and Monte Carlo simulations.

All data were taken on $26 \Omega \mathrm{cm}$ n-type Ge single crystals of (001) surface orientation. Prior to mounting the crystals were ultrasonically cleaned in ethanol. A clean surface was obtained by cycles of sputtering ( $800 \mathrm{eV} \mathrm{Ar}$ ions, $2 \mu \mathrm{A} \mathrm{cm}^{-2} 30 \mathrm{~min}$, angle of incidence $\left.45^{\circ}\right)$ and annealing $(850 \mathrm{~K}, 30 \mathrm{~min})^{6}$. During sputtering the crystals were also heated to about $700 \mathrm{~K}$ for about $15 \mathrm{~min}$ followed by slow cooling $\left(1 \mathrm{~K} \mathrm{~s}^{-1}\right)$. The base pressure of the uhv system was below $2 \times 10^{-8} \mathrm{~Pa}$. The ellipsometric measurements were performed with a rotating analyser ellipsometer (RAE) in the photon energy range $1.5-3.5 \mathrm{eV}$ before and after the ion bombardment. The Ge(001) surface has been bombarded by noble gases ( $\mathrm{Ne}, \mathrm{Ar}, \mathrm{Kr}$ ) at energies of 500 and $800 \mathrm{eV}$ with an angle of incidence of $45^{\circ}$ at room temperature. The sample current was $2 \mu \mathrm{A} \mathrm{cm}^{-2}$, yielding a total dose of 50 ions per surface Ge-atom after bombardment of half an hour. When the bombardment is terminated, the ellipsometric quantities $\psi$ and $\Delta$ still change, which can be explained by damage recovery at room temperature (self anneal behaviour). Therefore the optical data were measured half an hour after the ion bombardment was terminated. Auger electron spectroscopy (AES) show that an oxide overlayer must in any case be rejected.

The dielectric constants of our cleaned $\mathrm{Ge}(001)$ samples are in good agreement with Aspnes results ${ }^{2,7}$ on clean $\mathrm{Ge}(111)$ surfaces. For our LR analysis we used the dielectric constants of amorphous $\mathrm{Ge}$ as measured by Connell et $\mathrm{al}^{8}$. Interpretation of our measurements requires the dielectric function for nearly 'ideal' amorphous germanium, e.g. a minimum void fraction, microscopic roughness, and oxide overlayer thickness. As discussed in past studies, the dielectric function data of Connell $e t$ al satisfy these criteria.

The observed experimental data were analysed with the help of standard n-layer models and the EMA-theory ${ }^{5}$. The spectra of the ellipsometric parameters $\Delta$ and $\psi$ for each model considered are then evaluated using exact equations of ellipsometry. The linear regression analysis technique was then employed to minimise the differences between the calculated and experimental data. The unbiased estimator $(\alpha)$ in this study is given by:

$\alpha=\left[\frac{1}{N-p-1} \sum_{1}^{N}\left(a_{\text {exp }}-a_{\text {mod }}\right)^{2}+\left(b_{\text {exp }}-b_{\text {mod }}\right)^{2}\right]^{1 / 2}$.

$N=$ number of data points,

$p=$ number of fitted parameters,

$a, b=$ Fourier coefficients of sinusoidal components of the intensity

We have tried several models for interpretation of the optical measurements: Model I: completely amorphous toplayer. Model II: amorphous toplayer + voids $\left(\varepsilon_{\text {void }}=1-\mathrm{i} 0\right)$ fraction. Model III: amorphous toplayer + crystalline fraction.

The results of model I and model II are given in Table 1. A Monte Carlo computer program (TRIM 86) developed by Ziegler et $a l^{9}$ has been used which can determine the projected range, the range straggling and the final distribution of the ions in the solid.

The sum of the projected range $(x)$ and the range straggling $(\sigma)$ of the ions, $x+\sigma$, calculated from the Monte Carlo simulations is in good agreement with the measured thickness of the damaged layer if we assume a void free amorphous germanium toplayer. The thickness of an amorphous germanium toplayer with voids is in agreement with approximately $x+2 \sigma$ of the Monte Carlo simulations. Model III gives roughly a crystalline fraction of 0.5 and a thickness of about twice the value obtained with Monte Carlo simulations, so we have to reject this model.

Tauc proposed the following relation between the imaginary part $\varepsilon_{2 a}$ of the dielectric constant of amorphous germanium and 
Table 1. Unbiased estimator $(\alpha)$, thickness $(d)$, void fraction $\left(f_{v}\right)$ and optical gap $\left(E_{\mathbf{g}}^{\text {opt }}\right)$ for models I and II. The results of the Monte Carlo simulations (TRIM 86) are also given

\begin{tabular}{|c|c|c|c|c|c|c|c|c|}
\hline \multirow[b]{2}{*}{$\begin{array}{l}\text { Gas energy } \\
{[\mathrm{eV}]}\end{array}$} & \multicolumn{2}{|c|}{ Model I } & \multicolumn{3}{|c|}{ Model II } & \multirow[b]{2}{*}{$\begin{array}{l}E_{\mathrm{g}}^{\mathrm{opt}} \\
{[\mathrm{eV}]}\end{array}$} & \multicolumn{2}{|c|}{ Monte Carlo } \\
\hline & $\begin{array}{l}d \\
{[\AA]}\end{array}$ & $\begin{array}{l}\alpha^{2} \\
{\left[10^{-4}\right]}\end{array}$ & $\begin{array}{l}d \\
{[\AA]}\end{array}$ & $\begin{array}{l}\alpha^{2} \\
{\left[10^{-4}\right]}\end{array}$ & $\begin{array}{l}f_{\mathrm{v}} \\
{\left[10^{-2}\right]}\end{array}$ & & $\begin{array}{l}x+\sigma \\
{[\AA]}\end{array}$ & $\begin{array}{l}x+2 \sigma \\
{[\AA]}\end{array}$ \\
\hline $\begin{array}{r}\text { Ne } 500 \\
800\end{array}$ & $\begin{array}{l}35 \pm 3 \\
49 \pm 3\end{array}$ & $\begin{array}{l}2.14 \\
2.02\end{array}$ & $\begin{array}{l}43 \pm 3 \\
58 \pm 4\end{array}$ & $\begin{array}{l}1.67 \\
1.56\end{array}$ & $\begin{array}{l}8 \pm 2 \\
5 \pm 1\end{array}$ & $\begin{array}{l}0.99 \\
0.89\end{array}$ & $\begin{array}{l}35 \pm 3 \\
45 \pm 4\end{array}$ & $\begin{array}{l}48 \pm 5 \\
62 \pm 6\end{array}$ \\
\hline $\begin{array}{r}\text { Ar } 500 \\
800\end{array}$ & $\begin{array}{l}31 \pm 3 \\
39 \pm 3\end{array}$ & $\begin{array}{l}1.10 \\
0.91\end{array}$ & $\begin{array}{l}37 \pm 2 \\
45 \pm 2\end{array}$ & $\begin{array}{l}0.88 \\
0.63\end{array}$ & $\begin{array}{l}6 \pm 1 \\
5 \pm 1\end{array}$ & $\begin{array}{l}0.93 \\
0.72\end{array}$ & $\begin{array}{l}26 \pm 3 \\
33 \pm 3\end{array}$ & $\begin{array}{l}35 \pm 3 \\
45 \pm 4\end{array}$ \\
\hline $\begin{array}{r}\text { Kr } 500 \\
800\end{array}$ & $\begin{array}{l}24 \pm 3 \\
32 \pm 3\end{array}$ & $\begin{array}{l}0.94 \\
0.73\end{array}$ & $\begin{array}{l}31 \pm 2 \\
38 \pm 2\end{array}$ & $\begin{array}{l}0.54 \\
0.55\end{array}$ & $\begin{array}{r}10 \pm 1 \\
5 \pm 1\end{array}$ & $\begin{array}{l}0.87 \\
0.76\end{array}$ & $\begin{array}{l}24 \pm 3 \\
31 \pm 3\end{array}$ & $\begin{array}{l}31 \pm 3 \\
41 \pm 4\end{array}$ \\
\hline
\end{tabular}

the photoenergy $E(1.5-2.5 \mathrm{eV})^{10}$,

$\varepsilon_{2 \mathrm{a}} E^{2}=\mathrm{C}\left(E-E_{\mathbf{g}}^{\mathrm{opt}}\right)^{2}$.

The critical linear relationship between $\left(\varepsilon_{2 \mathrm{a}} E^{2}\right)^{1 / 2}$ and $E$ in the Tauc's plot lies above $1.5 \mathrm{eV}$, and this linear relationship is extrapolated to yield the optical gap $E_{\mathbf{g}}^{\text {opt }}$. The optical gap ranges from $0.72 \mathrm{eV}$ (Ar $800 \mathrm{eV})$ to $0.99 \mathrm{eV}(\mathrm{Ne} 500 \mathrm{eV}$ ), different from a constant value of $0.83 \mathrm{eV}$ for dc magnetron films ${ }^{1}$. However, an implicit result of ref $I$ is that there is no clear relationship between void fraction and optical gap, comparing differently prepared amorphous films. One thus has to be cautious to draw conclusions from optical gap values with respect to the void content of amorphous Ge films.

In conclusion, the damage depth of low energy ion-bombardment Ge samples as measured by spectroscopic ellipsometry is in good agreement with $x+\sigma$ of Monte Carlo calculations if we assume a void free amorphous toplayer. However, an amorphous toplayer containing a void fraction of about 5$10 \%$ can not be excluded. In this case the damage depth is in good agreement with the value $x+2 \sigma$ obtained from Monte Carlo calculations. The films are comparable with those obtained by dc magnetron sputtering.

\section{References}

${ }^{1}$ L J Pilione, K Vedam, J E Yehoda and R Messier, Phys Rev, B35, 9368 (1987).

${ }^{2}$ D E Aspnes and A A Studna, Surface Sci, 96, 294 (1980).

3 A M Holtslag, U C Slager and A van Silfhout, Surface Sci, 152/153, 1079 (1985).

${ }^{4}$ A H M Holtslag and A van Silfhout, Nucl Instrum Meth., B19/20, 585 (1987).

${ }^{5}$ A H M Holtslag and A van Silfhout, Phys Rev, B38, 10556 (1988). ${ }^{6}$ S D Kevan and N G Stoffel, Phys Rev Lett, 53, 704 (1984).

${ }^{7}$ D E Aspnes and A A Studna, Phys Rev, B27, 985 (1983).

${ }^{8} \mathrm{G}$ A N Connell, R J Temkin and W Paul, Adv Phys, 22, 643 (1973).

${ }^{9} \mathrm{~J} F$ Ziegler, J P Biersack and U Littmark, The Stopping and Range of Ions In solids, Vol 1. Pergamon, Oxford (1985).

${ }^{10} \mathrm{~F}$ Abeles, Optical Properties of Solids. North-Holland, Amsterdam (1972). 